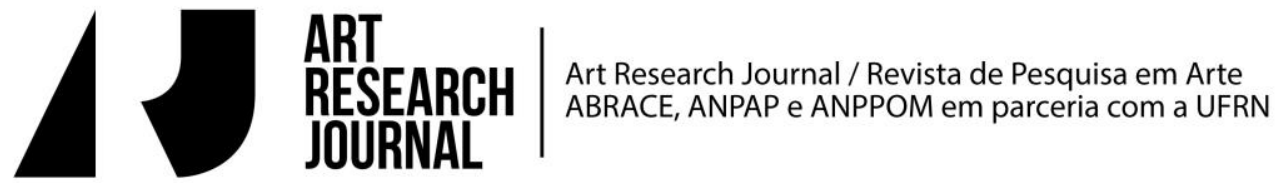

\section{O ofício do compositor hoje}

\author{
Marcos Câmara de Castro \\ Universidade de São Paulo \\ mcamara@usp.br
}

TRAGTENBERG, Lívio (org.). O ofício do compositor hoje. São Paulo, Perspectiva, 2012. Signos Música, 14. 368p. ISBN: 978-85-273-0947-9

Não deixa de ser animador ler na capa de um livro o título $O$ ofício do compositor hoje, organizado pelo talentoso Lívio Tragtenberg e que conta com uma escolha criteriosa que elegeu, por razões justificadas, Eli-Eri Moura, Marlos Nobre, Harry Crowl, Jorge Antunes e Amaral Vieira, numa difícil, porém representativa, escolha entre a vasta e diversificada produção contemporânea brasileira, mas que infelizmente esqueceu de convidar pelo menos uma compositora.

De início promissor, o texto do organizador menciona, talvez pela primeira vez na escassa bibliografia brasileira, "o processo da tradição ocidental de idealização e estetização na linguagem musical" (p. 14), o que promete uma crítica consistente desse e de outros fenômenos, como os privilégios ameaçados ao se tentar uma etnografia das práticas composicionais estabelecidas principalmente nas universidades. Admite que o compositor é um ser histórico, "não sendo impermeável ao mundo que o envolve" (p. 15) e que disputa o espaço social e um status como qualquer outro profissional.

Com o desenvolvimento da indústria do entretenimento continua, a criação e a execução musicais passam a ter um "valor de trabalho" e portanto remuneradas como se, em outras épocas, também não tivesse sido assim. A música gerou os primeiros "produtos duros", como o disco e o cinema e passou-se a exigir uma atividade diversificada do criador musical, além do refúgio na academia como uma "camuflagem". Afirma que o ensino de música deve acontecer "em bases totalmente diferentes" da "engenhoca" (sic) do ensino superior acadêmico, 
considerando o conceito de software como "síntese luminosa" e "ferramenta de iluminação em direção ao desconhecido, ao não criado, ao não habitual" (p. 18). Entendendo o ato da composição cada vez mais como um "ato de coordenação de elementos pré-dados", o organizador parece esquecer que sempre foi assim naquilo que nos acostumamos a chamar História da Música - que não é outra coisa do que a eleição de um cânone de acordo com o gosto de uma cultura dominante ou, no dizer de Huxley, a história contada pelos vencedores. Hoje o que se impõe é uma visão antropológica da diferença entre as práticas musicais no planeta, se quisermos, por algum motivo específico, narrar uma história das práticas musicais, como faz, ainda que de maneira restrita, a publicação História da Música do século XX de Cambridge (2004), organizada por Nicholas Cook e Anthony Pople. Enquanto os ingleses olharam para a realidade do século XX que não foi protagonizada apenas pela autoproclamada vanguarda e seus epígonos -, aqui os compositores se juntam em círculos restritos para falar de seus devaneios e alegorias, sem qualquer preocupação didática ou social, com as simpáticas exceções do próprio Tragtenberg, de Carlos Eduardo Amaral e a breve e decisiva participação de Tim Rescala, no último artigo do livro.

Tragtenberg menciona os restritos gêneros musicais a que o público tem acesso e que se acostumou a chamar de "música". Christopher Small, em 1987, num artigo esclarecedor, já fazia a conta de que, no repertório dito clássico, apenas cerca de cinquenta compositores têm sido tocados nas salas de concerto pelo mundo, depois da Segunda Guerra - o que não é novidade para quem reflete sobre a música de concerto. Nenhum compositor deste livro se atreve a percorrer a história ocidental da música, na trilha da invenção da vida de artista, ou da passagem do compositor-artesão ao compositor-independente, frutos maiores da evolução dos conceitos de gênio e de autonomia da obra de arte. Pensar o ofício do compositor hoje é mais do que fazer digressões em cima de ideias sem compromisso nem com a realidade nem com o rigor científico, entendido como busca de discussão entre pares. O livro acaba sendo uma tribuna onde cada um dos outros 10 autores convidados a depor (tirante Lívio, Carlos Eduardo, Ibaney Chasin e Tim Rescala) exibem seus esoterismos e seus discursos obscuros que querem parecer profundos.

O livro começa com os prolegômenos de Tragtenberg e parece querer aprofundar algumas questões, mas perde-se nos delírios narcisistas dos coautores. Os 
prolegômenos continuam numa direção promissora, ao falar da importação das questões e dilemas austro-germânicos e europeus que manteve a tradição vanguardista brasileira afastada de questões locais, como sempre mais preocupada em participar de um sonhado universalismo cuja referência é, e continua sendo, a metrópole europeia. ${ }^{1}$ Razão maior para que Argentina e México, e mesmo Peru e Chile, tenham mais inserção no mercado internacional da composição autodenominada erudita ("ex-rude"), do que o Brasil que continua sendo dominado pelo discurso europeu, branco e masculino. Pelo menos a misoginia já é uma das hipóteses de trabalho desta publicação...

O texto de Lívio Tragtenberg também traz interessantes citações de Morton Feldman, quando fala de amador e profissional da criação (p. 20 e ss); ou quando evoca superficialmente a questão da pureza como geradora das grandes tragédias humanas (p. 22). Terminada a leitura dos prolegômenos, o leitor certamente tentou sem sucesso estabelecer relações entre as letras de tamanho grande que permeiam o texto sem absolutamente nenhuma razão, a não ser a de parecer concretista, como é de praxe na literatura sobre o assunto, filiando-se a seus amigos do campo que teve nos poetas concretistas um dos grandes aliados e incentivadores.

O texto de Amaral explica, justifica, mas não convence do porquê de sua misoginia, ao deixar de fora as mulheres. Seu trabalho etnográfico de questionários e interpretações é louvável porque demonstra a preocupação com o rigor das informações, mas certamente teve dificuldade em interpretar os textos dos compositores. Marlos Nobre fala sobre "encomendas afetivas", "elaboração contínua mental" (p. 30-31) e "capacidade de sintetizar pessoalmente todas as experiências do outro" (p. 57). Amaral toca levemente sobre problemas reais como o pagamento de direitos autorais que afugentam os produtores fonográficos (p. 38), tema bem explorado por Rescala no final do livro. A "pouca capacidade de os compositores se agenciarem", segundo Amaral, é um dos fatores que dificultam "o ingresso no panteão da História da Música" (p. 39), confirmando o fetiche da composição erudita contemporânea.

Para muitos dos coautores, falar sobre ser compositor hoje é falar de sua filiação ao eixo de "música escrita, na tradição de Perotinus Magnus, Josqin (sic) de

\footnotetext{
1 Uma discussão lúcida e esclarecedora sobre vanguarda e subdesenvolvimento encontra-se em GULLAR, 1978.
} 
Près, Beethoven, Schoemberg (sic) e John Cage", como professa Emanuel Pimenta em seu texto pseudoconcretista (p. 76). Crowl reconhece que se um compositor peruano não residisse na Finlândia, talvez não tivesse merecido o Prêmio Irino (p. 60). ${ }^{2}$ Aqui no Brasil, a elite que monopoliza essas questões nunca se preocupou com a educação ou com a simples inteligibilidade do texto, preferindo dialogar entre pares e exibir seus supostos talentos singulares.

As influências desses compositores são geralmente ligadas aos "grandes eixos da produção da música atual" (Crowl, p. 53). Mas que música atual? A dos consultórios de dentista que nos acalmam e evitam que entremos em pânico? Ou a dos elevadores? Ou as trilhas de cinema e a música das rádios? Ou os holds dos telefones? A tradição da música de concerto, na qual os depoentes aspiram inserção, hoje é um ritual específico de contemplação de um museu imaginário que raramente inclui novos integrantes no panteão. Produção atual de quem?

Marlos Nobre atribui um sentido contrário ao conceito de pós-modernidade, quando afirma que ele é horizontal e a pluralidade é vertical e profunda (p. 58), ignorando que pós-modernidade é um olhar crítico sobre a modernidade e o desvendar das ideologias que estão na base de seus dogmas. O fato de o Brasil ainda não ter se inserido no cenário da música erudita contemporânea mundial é reflexo dessa alienação do campo interno. Ser compositor de música clássica hoje é como querer ser nobre numa sociedade democrática e capitalista. "Nobre" é Tim Rescala (p. 349-356) quando aborda o ofício de maneira prática, sem preocupações acadêmicas, mas com objetividade e pertinência, sem devaneios narcisistas.

Eduardo Seincman (p. 63-74) faz variações pessoais sobre "alguns temas de Sartre", de onde se lê coisas como: "todas as obras novas dialogam explícita ou implicitamente com as obras que Ihes antecederam"; chama a atenção para o contexto de recepção como co-artífice do belo; cita o Doutor Fausto de Thomas Mann; discute a comunicabilidade da obra musical segundo critérios idealistas e valoriza o silêncio.

Emanuel Pimenta diz que "Debussy fazia e desencadeou em Alban Berg, em Anton Webern, Liszt e Mallarmé - num outro espectro de sintonia" (p. 77); ou "Acabou por desvendar Stockhausen, Pierre Schauffer (sic) e Varèse - na sua

\footnotetext{
2 Fato que lembra a carreira de Vargas Llosa, outro peruano, que ganhou o Prêmio Nobel de Literatura, residindo em Paris.
} 
segunda vida" (p. 80). Flô Menezes conclui seu depoimento neoconcretista diminuindo progressivamente o tamanho da letra até o ilegível e aconselha "a lupa apropriada à sua leitura".

Em que pesem a militância e o comportamento combativo de Jorge Antunes ( $p$. 103-139), fica difícil entendê-lo fora da perspectiva de Hobsbawm, quando diz em $A$ era dos extremos (1995, p. 497) que "Com base na analogia entre ciência e tecnologia, o 'modernismo' tacitamente supunha que a arte era progressista, e, portanto, o estilo de hoje era superior ao de ontem. Era por definição, a arte da avant-garde, termo que entrou no vocabulário crítico na década de 1880 , isto é, de minorias que em teoria esperavam um dia conquistar a maioria, mas na prática estavam satisfeitas por não o terem feito ainda".

Ibaney Chasin (p. 141-198) promove uma reflexão filosófica de caráter idealista entre "o artista e a arte dos séculos XV e XVI e os nossos dias" em que observa os conceitos de arte no mundo, arte sem mundo, subjetivação, banalização, cientificismo, misticismo e o conceito de arte a partir das vanguardas, participando do pensamento dominante da tradição vanguardista e estabelecendo as relações possíveis dentro de um campo onde tudo é possível, mas que acredita na linha evolutiva, independente das linguagens artísticas, quase sem vínculo com o concreto. Um texto sóbrio que pode até ser inspirador.

Mannis (p. 199-207) discute as "novas formas de atuação" do compositor, a partir dos conceitos de transição, mudança, mutação e da expansão industrial a partir do século XIX, usando para isso mapas conceituais que descrevem atividades de invenção e expressão entre os séculos XVI e XIX e na atualidade. Conclui sugerindo uma reflexão sobre "grades curriculares aprisionadas" que desovam anualmente "bacharéis sem perspectivas profissionais", reclamando por uma renovação dessas grades no sentido de "intervir construtivamente no processo de mutação da sociedade". ${ }^{3}$

Scarassatti (p. 209-242) retoma questões como a vastidão do campo de atuação do compositor hoje, a abrangência do fazer musical, emblemas sonoros, emblemas da memória, "formas complexas que potencializam a obtenção do som" e suas experiências no banheiro de um apartamento no bairro de Benfica,

\footnotetext{
3 A respeito das "grades curriculares aprisionadas", recomendo a leitura de BELLARD-FREIRE, 2010. Sobre o "processo de mutação da sociedade", sugiro MORIN, 2011, sobretudo o capítulo 2, "Réforme de l'Éducation", p. 251-268.
} 
em Portugal (sem mencionar a cidade). Considera o gesto da composição emblemático, "no sentido da aglutinação simbólica", sugere a "retração do ego compositor para gerar espaço e situações de criações singulares, para que estas se desdobrem em outras retrações e, por consequência, em aberturas de espaço. É processo alquímico coletivo, desempenhado por singularidades".

Rodolfo Caesar (p. 243-266) fala em neurociência, multirelativismo cultural, "em defesa de nossa preservação" como "mantenedores de uma cultura relativamente passada, interessante, rica, merecedora de um lugar forte e atuante no meio de tantas forças antagônicas, sendo exatamente nossa errância o melhor meio de conservar o conhecimento específico que ficou [...] conhecido como História da Música" (p. 244). Cita Susan McClary a respeito do "poder do lobby da vanguarda no meio do ensino superior", mas com a ressalva de que a autora fala de uma outra modernidade que não é a dele. Critica também a impregnação pós-modernista de "tinturas nacionalistas, jdanovistas, lukacsianas e populistas" que se parecem a um "projeto antimoderno, empregando anacronicamente modelos sem encaixe". Um pós-modernismo para combater um modernismo que, "no Brasil, nem chegou". Defende o mito da forma, bem ao estilo do discurso hegemônico europeu que lhe outorga um valor sine qua non, mas no processo da eleição do cânone, ${ }^{4}$ a crítica e a análise estrutural são construções a posteriori. Caesar encerra suas reflexões afirmando que seu ofício é o da dúvida.

Sérgio Pinto (p. 267-284) relata sua descoberta de que não existe música "com a qual todo mundo se identifica", que pelo menos é uma maneira de admitir que qualquer hegemonia é arbitrária. Reconhecendo que o "desenvolvimento histórico da música ocidental foi possível graças à aquisição da escrita musical, ${ }^{5}$ o que permitiu o surgimento de uma criação reflexiva, planejada como plantas arquitetônicas em que cada elemento de construção é detalhado e pensado em função da estrutura da obra", Pinto afirma que as manifestações populares sofreram a partir da escrita uma "higienização tonal" e narra experiências musicais introspectivas, sem considerar toda a tradição oral subjacente à tradição clássica.

\footnotetext{
${ }^{4}$ cf. WEBER, 2010, p. 336-355.

5 Sobre "a posição especial da música ocidental" e o desenvolvimento de sua escrita, sugiro a leitura de Wiora, 1965, p. 125-145.
} 
Silvio Ferraz (p. 285-306) retoma o dogma da estrutura ao reverso, percebendo em Villa-Lobos uma música de "diversidades sobrepostas" e "ciclos de sonoridades", dispensando-o das exigências das "medidas justas de contraponto" europeias. Compor "é inventar um campo de problemas", diz, e prefere "o sino da igreja à distância ao invés do ritmo frenético do DJ estourando em um fone de ouvido". Traz Guimarães Rosa em seu auxílio para dizer que o escritor "faz a literatura mergulhar no dizer do homem do sertão, para ligar o homem à onça, a onça ao som, como se uma língua estivesse nascendo enquanto estamos lendo", como na música: "ponto em que se inventa uma língua que se desdobra e se inventa ao mesmo tempo em que é escutada, sempre pela primeira vez".

Silvio Gallo (p. 307-347) discute o ato de criação em Tom Zé, de maneira instrutiva, e finalmente a voz destoante de Tim Rescala (p. 349-356) que evoca o papel social, a interlocução com a sociedade, o afunilamento das possibilidades criativas com a eliminação das orquestras das rádios e tevês e o desafio de "saber equilibrar-se entre a linha tênue que separa a atividade profissional da atividade criadora, que somam-se (sic) numa só". Tim Rescala discute também a atuação do ECAD e a extinção do CNDA, pelo governo Collor, que o regulava e o fiscalizava.

\section{Arremedo, exemplo, educação}

George Ives já alertava seu filho Charles, ao preveni-lo dos perigos de se prestar demasiada atenção ao som e, com isso, perder a música. ${ }^{6} \mathrm{O}$ que este livro mostra é que os compositores, homens e brancos, escolhidos pelo organizador estão bem afinados em suas conviç̧ões, o que denota um grupo de admiração mútua que, ao ser publicado pelo selo Perspectiva, Coleção Signos Música - que já publicou Willy Corrêa, Leibowitz, Iazzetta, Didier Guigue, Augusto de Campos, além do próprio Tragtenberg antes, entre outros -, impõe-se como um pensamento e uma natureza de abordagem comprometida em maior ou menor grau com as tradições hegemônicas da vanguarda europeia, e de maneira quase subserviente consideram seus epígonos e seus dogmas como pontos de partida.

Não se discutiram a produção das mulheres, dos negros, as práticas amadoras e nem a educação como sintomas de um possível pluralismo de interpretações, absolutamente ausente neste livro. Exceções já feitas, num livro com este título,

\footnotetext{
${ }^{6}$ Cf. IVES,1973, p.132: "Don't pay too much attention to the sounds - for if you do you may miss the music".
} 
era de se esperar uma postura um pouco mais abrangente, incluindo um espectro maior de depoimentos de pessoas envolvidas com composição...ou mesmo uma maior preocupação com a educação ou com o papel social do compositor. O jovem que ingressa no campo da composição vai ler e tomar isso como exemplo de como se deve pensar a composição hoje.

A História da Música permanece o principal fetiche, junto com a obsessão do som como princípio musical e não a música como uma prática social compartilhada dentro de uma cultura determinada. Mesmo com a globalização das culturas, não haverá traço de nada disso se desligarmos a tomada, pois o que está em jogo não é a música, mas sim o som, o panteão da história e o dogma da forma e da estrutura que restringiu as análises, ignorando qualquer possibilidade de contextualização como forma insubstituível de construir um universalismo intelectual. Música entendida não como produto de uma mentalidade, mas como um conjunto arbitrário de signos que tem história própria, independente da tradição de que faz parte - o que atravanca sua compreensão na medida em que a afasta do homem, da sociedade e da educação.

Os coautores do livro dão a sensação de que ser "compositor erudito contemporâneo" é o mesmo que se dizer um gênio incompreendido que a História finalmente virá reabilitar. Se os compositores eruditos contemporâneos não são relevantes no mercado musical atual, não é por causa do DJ ou da Indústria da Cultura, mas porque seu pensamento está atrelado ao da história da música ocidental e não consideram a diáspora dessa tradição como algo a ser reelaborado e reapropriado. 


\section{Referências bibliográficas}

BELLARD-FREIRE, Vanda. Música e sociedade: uma perspectiva histórica e uma reflexão aplicada ao ensino superior de Música. 2. ed. rev. e ampl. Florianópolis, Associação Brasileira de Educação Musical, 2010.

GULLAR, Ferreira. Vanguarda e subdesenvolvimento. Rio de Janeiro, Editora Civilização Brasileira, 1978.

HOBSBAWM, Eric. A era dos extremos. São Paulo, Cia das Letras, 1995.

IVES, Charles E.. Memos, ed. John Kirkpatrick, London, Calder \& Boyars, 1973.

MORIN, Edgar. La voie, Librairie Arthème Fayard, 2011.

SMALL. Christopher. The Social Character of Music. Performance as ritual: sketch for an enquiry into the true nature of a symphony concert. In: Lost in Music. Culture, Style and the musical event. Edited by Avron Levine White and Kegan Paul. London and New York: Routledge, 1987.

WEBER, William. The history of the Musical Canon. In: COOK, Nicholas \& EVERIST, Mark (editors). Rethinking Music. Oxford, Oxford University Press, 2010.

WIORA, Walter. The Four Ages of Music. Trad. M. D. Herter Norton. New York: W.W. Norton \& Co, 1965. 